\title{
Structural Relationships in Small Molecule Interactions Governing Gas-Phase Enantioselectivity and Zwitterionic Formation
}

\author{
Xin Cong, Gregg Czerwieniec, Erica McJimpsey, Seonghee Ahn, \\ Frederic A. Troy, and Carlito B. Lebrilla \\ Departments of Chemistry, Biochemistry, and Molecular Medicine, School of Medicine, University \\ of California, Davis, California, USA
}

\begin{abstract}
Gas-phase zwitterionic amino acids were formed in complexes of underivatized $\beta$-cyclodextrin through reactions with a neutral base, $n$-propylamine. The reaction was performed in the analyzer cell of an electrospray ionization-Fourier transform mass spectrometer. Most of the natural amino acids were studied with three cyclodextrin hosts including $\alpha^{-}, \beta-$, and $\gamma$-cyclodextrin to understand better the structural features that lead to the stabilization of the zwitterionic complexes. Molecular dynamics calculations were performed to provide insight into the structural features of the complexes. The rate constants of the reactions were obtained through kinetic plots. Examination of both L- and D-enantiomers of the amino acid showed that the reaction was enantioselective. The reaction was then employed to analyze mixtures of Glu enantiomers naturally occurring in the bacteria Bacillus licheniformis. (J Am Soc Mass Spectrom 2006, 17, 442-452) (C) 2006 American Society for Mass Spectrometry
\end{abstract}

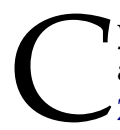

yclodextrins (CDs) are torus-shaped, cyclic sugars that form inclusion complexes in solution [1, 2]. The most common forms of $\mathrm{CD}, \alpha-\mathrm{CD}, \beta-\mathrm{CD}$ and $\gamma-\mathrm{CD}$, are composed of 6,7 , and $8 \alpha-1,4$ glucose subunits, respectively. The CD environment is characterized by a hydrophobic cavity and a hydrophilic rim. In solution, the cavity of $C D$ provides a receptive host for the incorporation of hydrophobic compounds to form a host/guest complex [3-5]. The use of electrospray ionization, a soft ionization technique, allows the transfer of these intact complexes as charged species into the gas-phase. Mass spectrometry provides a rapid and sensitive diagnostic tool for evaluating CD inclusion complexes based on the ion signal of the corresponding $m / z$ value [6-11].

The study of gas-phase complexes provides a relatively well-defined system for studying intermolecular interactions. It also allows better understanding of the intrinsic properties of noncovalent complexes [12]. Cyclodextrin complexes are particularly attractive as they provide highly defined if not rudimentary systems for studying host-guest complexes. For these reasons, they have been used as models for enzyme-substrate interactions as well as solvation shells for the stabilization of highly energetic structures [13]. CDs have also been proposed as potential drug delivery devices [3-5].

Published online February 14, 2006

Address reprint requests to Dr. C. B. Lebrilla, Departments of Chemistry, Biochemistry and Molecular Medicine, School of Medicine, University of California, One Shields Ave., Davis, CA 95616, USA. E-mail: cblebrilla@ucdavis.edu
These studies could provide further characterization for these types of applications [14].

Gas-phase complexes of tri-O-methyl $\beta$-cyclodextrin $\left(\beta-\mathrm{CD}^{*}\right)$ and di-O-methyl $\beta$-cyclodextrin $\left(\beta-\mathrm{CD}^{\circ}\right)$ with protonated amino acids (AA) undergo exchange reactions with amines in the gas-phase $[15,16]$. For example, the protonated $\beta$-CD ${ }^{*}$-amino acid complex, $\left[\beta-\mathrm{CD}^{*}: \mathrm{AA}+\mathrm{H}\right]^{+}$, reacts with an alkyl amine to produce the protonated $\beta-\mathrm{CD}^{*}$-alkylamine complex and a neutral amino acid, which is released from the $\beta$-CD* cavity after proton transfer (Scheme 1 ). The net reaction is the replacement of the amino acid by the alkylamine in the cavity of $\beta$-CD* resulting in a gas-phase guestexchange reaction. The interactions of the guest molecule with the hydrophobic cavity and the hydrophilic rim of $C D$ are known to play important roles in stabilizing the charge on the protonated amino acid [11,17]. The intermolecular hydrogen bonding interaction between the hydroxyl groups in the CD ring and the positive charge on the amino acid result in very stable complexes. In order for the exchange reaction to occur, the proton of the amino acid must be transferred to the amine. This proton transfer between the protonated amino acid and the gaseous amine is the essence of the exchange reaction. The equilibrium of this reaction is dictated by both the relative gas-phase basicities of the amine gas and the amino acid as well as the structural characteristics of the CD:AA guest/host complex.

We have previously shown enantiospecific gasphase guest-exchange reactions utilizing permethylated cyclodextrin and discussed the structural and chemical characteristics of the guest and host that lead to enan- 
$\left[\beta-\mathrm{CD}^{*}: \mathrm{AA}+\mathrm{H}\right]^{+}+$Base $\longrightarrow\left[\beta-\mathrm{CD}^{*}: \mathrm{Base}+\mathrm{H}\right]^{+}+\mathrm{AA}$

Scheme 1. The gas-phase reaction of the amino acid complex with derivatized $\beta$-cyclodextrin (both $\beta$-CD ${ }^{*}$ and $\beta$-CD ${ }^{\circ}$ ) react with gaseous amines. The amino acid is replaced by the alkyl amine base in the cavity of the $\beta$-cyclodextrin.

tioselectivity. Using this reaction, we probed the structure of gas-phase complexes $[16,18,19]$ and determined enantiomeric excess of amino acids and pharmaceutical compounds $[14,20,21]$. Subsequently, other gas-phase methods have been used for determining enantiospecificity [22]. Radiolysis, Fourier-transform ion cyclotron resonance mass spectrometry (FTICR-MS), and resonance-enhanced multiphoton ionization time-of flight (REMPI-TOF) spectroscopy are techniques previously used for gas-phase chiral recognition [12, 23-28]. Cooks et al. performed gas-phase chiral analysis of enantiomeric amino acid mixtures by using competitive fragmentation of trimeric transition-metalbound complexes with mass spectrometry [29-37]. In this method, protonated diastereomeric complexes containing transition-metal molecules and enantiomers of analyte were generated in solution and then transferred to gas-phase where they underwent collision induced dissociation (CID). The relative stability of the diastereomeric complexes were revealed by their different dissociation patterns. Recently, it was found that the type of binding ion plays a key role in chiral recognition $[38,39]$. Sawada et al. utilized modified crown ether as a chiral selective compound, which formed noncovalent diastereomeric adducts with analyte enantiomers. The quantification was done by measuring the relative peak intensity of the complexes in mass spectrometer [4047]. Speranza applied ESI-MS ${ }^{n}$ CID and REMPI-TOF methodologies to measure the fragmentation thresholds of diastereomeric clusters [19, 23, 25, 32, 48, 49]. They found that the chiral recognition was very sensitive to cavity size and hydrophilic/hydrophobic properties of the chiral receptor $[24,50]$. The same group also used gas-phase guest exchange reactions between diastereomeric adducts and chiral or achiral reactants $[27,51-53]$.

The existence of the zwitterionic species in the gasphase using underivatized cyclodextrin $(\mathrm{CD})$ as a stabilizing agent has previously been shown [13]. Until this point most guest exchange reactions were performed with permethylated or partially methylated CDs. An additional reaction channel is observed corresponding to the formation of a ternary complex (Scheme 2) when complexes of amino acids and underivatized $\beta$-cyclodextrin, $[\beta \text {-CD:AA }+\mathrm{H}]^{+}$are reacted with alkyl amine. The ternary complex consists of a

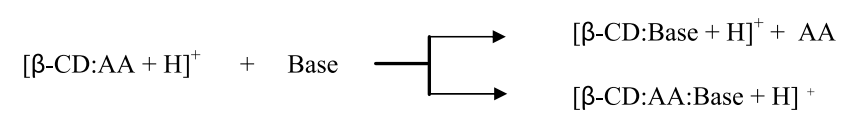

Scheme 2. Two reaction pathways exist for protonated complexes of underivatized $\beta$-cyclodextrin, $[\beta \text {-CD:AA }+\mathrm{H}]^{+}$, a guest exchange reaction and ternary complex formation.

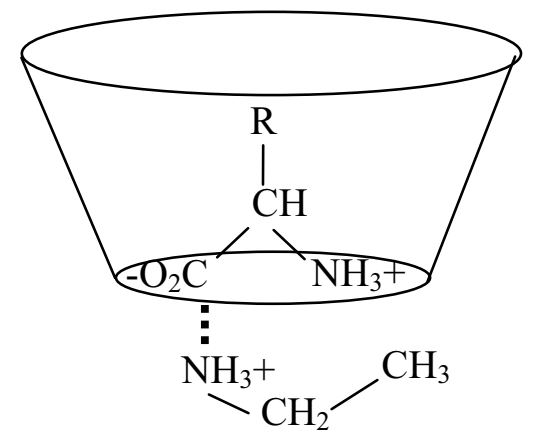

Scheme 3. Proposed structure of gas-phase zwitterionic amino acid in the cavity of cyclodextrin (represented as a toroidal cavity). The positive charge of the protonated amine is suspected to coordinate with the carboxyl group of the amino acid. The zwitterionic amino acid is then stabilized through hydrogen bonding to the cyclodextrin lower rim.

$\beta$-CD with both the protonated amino acid and the alkyl amine reagent complexed to the $\mathrm{CD}$ host, $[\beta-\mathrm{CD}$ : $\mathrm{AA}:$ Base $+\mathrm{H}]^{+}$. It was concluded that the ternary complex is the product of gas-phase zwitterion formation [13]. The possible interactions in the complexes are shown in Scheme 3 and Scheme 4. The neutral species of amino acids are more stable relative to the zwitterionic form in the gas-phase due to the unfavorable separation of charge states [54-57]. However, the unique interactions in cyclodextrin provide an environment that is capable of stabilizing the amino acids in the zwitterionic form. The intrinsic properties of zwitterionic amino acids are of fundamental interest as they affect the general properties of proteins [58, 59].

In this paper, we detail the structural and chemical requirement for zwitterion formation and investigate the enantioselectivity of the zwitterion formation. Several oligosaccharide hosts are examined to assess the different host structures' abilities to stabilize zwitterion formation in complexes of amino acids.

\section{Experimental}

\section{Materials}

All L-amino acids were purchased from Research Plus Inc. (Denville, NJ). All D-amino acids, n-propylamine,

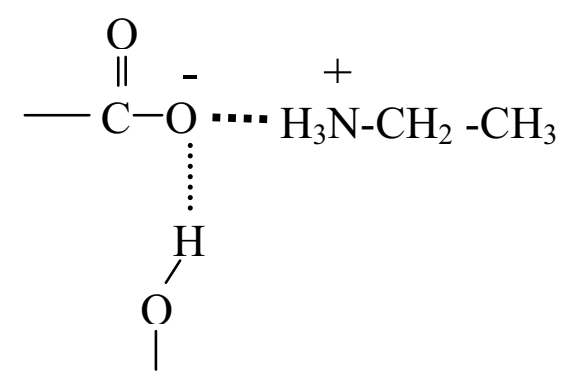

Scheme 4. The hydroxyl groups of the cyclodextrin host can stabilize the salt bridge-zwitterionic complexes through hydrogen bonding. 
ethylenediamine, underivatized $\alpha$-cyclodextrin $(\alpha$-CD), underivatized $\beta$-cyclodextrin $(\beta$-CD), and underivatized $\gamma$-cyclodextrin $(\gamma$-CD) were obtained from Sigma Chemical Co. (St. Louis, MO). Underivatized maltoheptaose was purchased from Aldrich Chemical Co. (Milwaukee, WI). Glacial acetic acid was purchased from Fisher Scientific (Fair Lawn, NJ). All chemicals were used without further purification. The silica tubing used for the microspray tips was obtained from Polymicro Technologies Inc. (Phoenix, AZ).

\section{Gas-Phase Reactions}

All the experiments were performed on a home-built external source electrospray ionization Fourier transform mass spectrometer (FTMS) equipped with a 4.7 tesla superconducting magnet. The instrument has been described in detail in previous publications [60, 61]. Solutions of the cyclodextrin $(0.01 \mathrm{M})$, maltoheptaose $(0.01 \mathrm{M})$, and the amino acids $(0.01 \mathrm{M})$ were prepared in a 50/50 (vol/vol) water/methanol solution. The oligosaccharide:amino acid complex solutions were prepared by mixing the cyclodextrin with a 10- to 50-fold excess of the amino acid. The final concentration of cyclodextrin in the solution was $1.0 \times 10^{-5} \mathrm{M}$. An aliquot of $0.5 \mu \mathrm{L}$ glacial acetic acid was then added to the solution. The complex solution was applied to the electrospray ionization source at a pump rate of $15 \sim 20$ $\mu \mathrm{L} / \mathrm{h}$. The electrospray voltage was $2.05 \mathrm{kV}$. The temperature of the desolvating capillary was maintained at $150 \sim 180^{\circ} \mathrm{C}$. The alkyl amine was introduced to the ICR cell by a variable leak valve after several freeze-thaw cycles to a pressure of $1 \sim 3 \times 10^{-7}$ torr. The gas-phase reaction was monitored as a function of time; the rate constants were obtained from the pseudo-first-order kinetic plots by plotting $\ln \left(I / I_{0}\right)$ versus $t$, where $I$ is the intensity of the complex of amino acid and cyclodextrin at time $t$ and $I_{0}$ is the sum of the intensities of the complex, the exchanged product, and the ternary product.

\section{Molecular Dynamics}

Molecular dynamics calculations were performed using the InsightII/ Discover program (Biosym Corp., San Diego, CA). For global minimization, heating/annealing cycles were performed using consistent valence force field (CVFF) to optimize the structure of underivatized $\beta$-CD:amino acid complexes. The details of these methods were published previously $[16,62]$. To create the ternary complex with underivatized $\beta-C D$, the $\beta$-CD:amino acid complex structure was obtained through the same heating/annealing cycles. The lowest energy structure from the calculation was then used by removing the proton from the carboxyl group of the amino acid in the CD to the alkylamine placed in the proximity of the narrow rim. This complex was optimized without the heating/annealing cycles, which tended to dissociate the ternary complex.

\section{Results and Discussion}

It was previously determined in this laboratory that zwitterion formation in underivatized $\beta$-cyclodextrin $(\beta-C D)$ complexes was favored by amino acids with higher gas-phase basicities (GBs), while those with low GBs favored exchange [13]. A protonated amino acid in the CD cavity has at least two acidic sites, the neutral carboxylic acid group and the ammonium group. In amino acids with basic side chains, the side-chain can also be involved. In complexes with amino acids of high $\mathrm{GB}$, deprotonation of the carboxylic acid becomes competitive to yield the zwitterion species. Amino acids with low GB, such as Gly, Ala, Cys, and Val yielded only guest-exchange products in the $\beta$-CD host. No reaction was observed when the amino acid was significantly more basic than the alkyl amine gas. For instance when $n$-propylamine (nPA) is used as the base, complexes of His, Lys, and Arg with $\beta$-CD do not react at all. In order for these amino acids to react, a more basic compound such as amine ethylenediamine (EDA) was needed.

Gas-phase basicity is not the only factor that dictates the formation of zwitterions in CD. Structural compatibility between the guest and the host molecules creates the conditions for a CD "solvation shell" to stabilize the zwitterion complex. To study this relationship, $\alpha-\mathrm{CD}$, $\beta-C D, \gamma-C D$, and maltoheptaose were examined to determine their abilities to stabilize the zwitterions. The cavity size increases from the six-member $\alpha$-cyclodextrin to the eight-membered $\gamma$-cyclodextrin. The average cavity sizes have been determined to be 5.0, 6.2, and 7.9, respectively [5]. Maltoheptaose (Mhep), the linear ana$\log$ of $\beta$-cyclodextrin, was also examined.

\section{The Effect of Host Molecule Cavity Size on Zwitterion Stability}

Table 1 lists the gas-phase products of the amino acids with the various host molecules. The amino acids are listed in the order of increasing gas-phase basicity [63].

With $\alpha$-CD, only proline forms the zwitterionic species when reacted with the base $n$-propylamine (nPA). This is evidenced by the dominant $\mathrm{m} / \mathrm{z}$ peak corresponding to the ternary complex (Figure 1). Present in the spectrum are the peaks corresponding to the exchange reaction $[\alpha-\mathrm{CD}: \mathrm{Npa}+\mathrm{H}]^{+}$and ternary complex formation $[\alpha-\mathrm{CD}: \text { Pro:nPA }+\mathrm{H}]^{+}$at $m / z 1033$ and 1148, respectively. Also present in the spectra is the unreacted complex of proline and $\alpha-\mathrm{CD},[\alpha-\mathrm{CD} \text { :Pro }+\mathrm{H}]^{+,}$at $m / z$ 1089.

The low-energy structure from CVFF modeling of $[\alpha \text {-CD:Pro }+\mathrm{H}]^{+}$is shown in Figure 2a. Pro is a compact amino acid-one with the side-chain fully encapsulated even in $\alpha$-CD. Both the ammonium and the carboxylic group can interact with the narrow rim while allowing the narrow rim to further interact with the incoming nPA. No other amino acid is able to interact in this way. For comparison, the glutamic acid: 
Table 1. Products from the reaction of the D-amino acidcyclodextrin(and maltoheptaose) complexes with nPA and EDA

\begin{tabular}{|c|c|c|c|c|}
\hline Amino acid & $\mathrm{a}-\mathrm{CD}$ & $\beta-C D$ & $\gamma-C D$ & Mhep \\
\hline Gly & $E$ & $E$ & $E$ & $E$ \\
\hline Ala & E & $E$ & $E$ & - \\
\hline Cys & $E$ & $E$ & $\mathrm{E} / \mathrm{T}$ & $E$ \\
\hline Asp & $E$ & $E$ & $\mathrm{~T}$ & - \\
\hline Val & $\mathrm{E}$ & $E$ & $\mathrm{E} / \mathrm{T}$ & $\mathrm{E}$ \\
\hline Glu & $\mathrm{E}$ & $\mathrm{T}$ & $\mathrm{T}$ & - \\
\hline Leu & $E$ & $E / T(10: 5)$ & $\mathrm{T}$ & $E$ \\
\hline Ser & E & E & $\mathrm{E} / \mathrm{T}$ & $E$ \\
\hline Ile & $\mathrm{E}$ & $E / T(10: 2)$ & $\mathrm{T}$ & - \\
\hline Pro & $E / T$ & $\mathrm{E} / \mathrm{T}(10: 8)$ & $\mathrm{T}$ & $\mathrm{E}$ \\
\hline Thr & $E$ & $E$ & $\mathrm{~T}$ & $E$ \\
\hline Phe & $E$ & $E / T(7: 10)$ & $\mathrm{T}$ & $E$ \\
\hline Asn & E & $\mathrm{T}$ & $\mathrm{T}$ & - \\
\hline Tyr & E & $\mathrm{E} / \mathrm{T}(2: 10)$ & $\mathrm{E} / \mathrm{T}$ & $\mathrm{E}$ \\
\hline Gln & E & $\mathrm{T}$ & $\mathrm{T}$ & - \\
\hline Met & E & $\mathrm{T}$ & $\mathrm{T}$ & E \\
\hline Trp & E & $\mathrm{T}$ & $\mathrm{T}$ & - \\
\hline $\mathrm{His}$ & $E$ & $\mathrm{~T}$ & - & - \\
\hline Lys & - & $\mathrm{T}$ & - & - \\
\hline Arg & - & $\mathrm{T}$ & - & - \\
\hline
\end{tabular}

$\mathrm{E}=$ Exchange product

$\mathrm{T}=$ Ternary complex product

$\alpha$-CD complex, $[\alpha-\mathrm{CD}: \mathrm{Glu}+\mathrm{H}]^{+}$, which did not yield the ternary complex, was also modeled (Figure $2 b$ ). The most favorable structure for this complex places the side-chain outside the cavity while still maintaining the interaction between narrow rim with both amine and the carboxylic acid groups. The side-chain prevents the $\mathrm{nPA}$ from simultaneously interacting with the nascent carboxylate and the narrow rim.
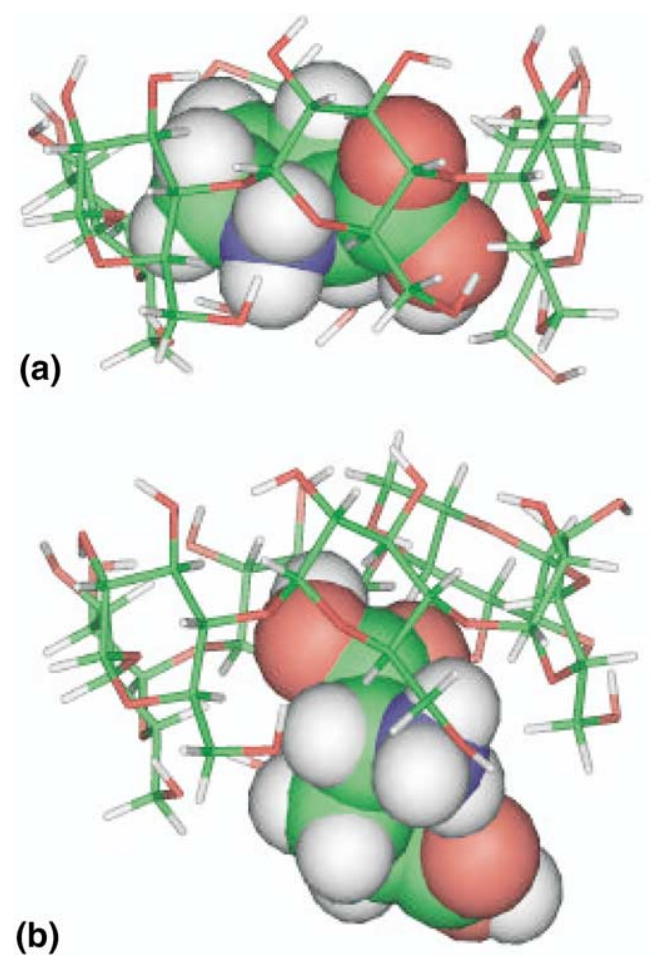

Figure 2. Low energy structures of [a-CD:Pro $+\mathrm{H}^{+}(\mathbf{a})$ and $[\mathrm{a}-\mathrm{CD}: \mathrm{Glu}+\mathrm{H}]^{+}(\mathbf{b})$ complexes. Pro was fully enclosed in the host. Glu yielded a structure where the side chain protruded away from the rim. (Color code for atoms: green $=\mathrm{C}$; white $=\mathrm{H}$; red $=$ $\mathrm{O}$; blue $=\mathrm{N}$ ). The lower rim is the narrow rim of $\mathrm{CD}$.

The cavity of $\beta-\mathrm{CD}$ is larger than that of $\alpha-\mathrm{CD}$, and provides a less confined space for the amino acid. The amino acids therefore have more freedom to rearrange

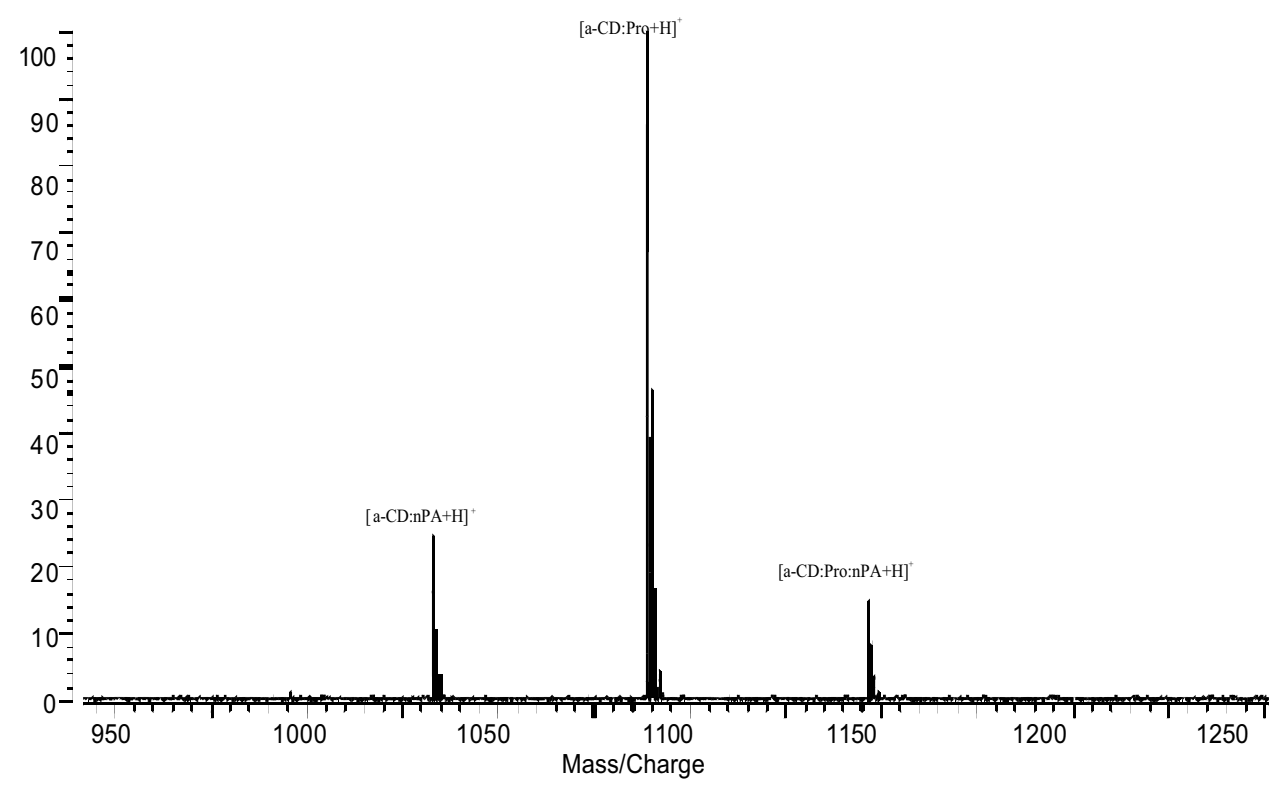

Figure 1. The reaction of $[\mathrm{a}-\mathrm{CD}: \mathrm{Pro}+\mathrm{H}]^{+}$produced the ternary complex product $[\alpha-\mathrm{CD}$ :Pro:nPA + $\mathrm{H}]^{+}$with $n$-propylamine. The reaction time is $30,000 \mathrm{~ms}$. The pressure of nPA was $1.7 \times 10^{-7}$ torr. 
and to interact favorably and yield zwitterions. Of the 20 amino acids, only six did not form zwitterionic products; Gly, Ala, Cys, Asp, Val, Ser, and Thr. In general, amino acids of higher basicity can be stabilized as zwitterions through formation of salt bridge with the base. However, steric constraints within the $\beta$-CD hosts are still evident as both Ser and Thr do not. Based on basicity arguments, Ser and Thr should form zwitterionic complexes (Table 1) because amino acids with lesser GBs do form the respective ternary complexes. Formation of the ternary complex with Ser and Thr is constrained by the specific interaction of the guest with the host. Molecular modeling of Ser in the $\beta$-CD cavity suggests a host-guest interaction that prohibits the simultaneous interaction of the protonated amine and the carboxylic acid with the narrow rim-a requisite for zwitterion formation [13]. Also shown in Table 1 are the ratios of the exchange products to the ternary products for the D-amino acids which undergo both reactions. For Leu and Ile, a mixture of exchange and ternary product were observed. In both cases the exchange product is dominant, however the ratio of exchange product to ternary product for Leu (10:5) was higher than that for Ile (10:2) despite the slightly lower GB of the former [63]. Tyr and Phe yielded a mixture of exchange and ternary product with ratios of 2:10 and $7: 10$, respectively. Tyr has a greater GB than Phe, and the reactions follow the known trend of compounds of high basicity favoring the zwitterions product.

For the $\gamma$-CD host, all amino acids with the exception of Gly and Ala produce the zwitterion complex (Table 1 ). In contrast to $\alpha-C D$, where the spatial constraints of the cavity limited ternary formation, the cavity of $\gamma$-CD is relatively spacious and can readily accommodate all amino acid zwitterion complexes. The inability Gly and Ala to form the ternary complex may simply be the result of relatively low GB. Other amino acids, namely Cys, Val, Ser, and Tyr, formed a mixture of exchange and zwitterionic products. Cys, Val, and Ser have relatively low GB and still yield guest exchange reactions. Tyr, however, has a relatively high GB yet still exhibited a mixture of products including those due to exchange.

Maltoheptaose (Mhep), the linear analog of $\beta-C D$, was also investigated as a host molecule. It is more flexible than the closed cyclic structure and its "pseudo" cavity provides a structure that can orient itself to better interact with the guest molecule. In all amino acid/ Mhep complexes studied, only guest exchange reaction product was observed (Table 1). Zwitterion formation does not occur in Mhep, possibly because its helical is not amenable to the narrow-rim interactions found in the cyclodextrins.

From the above discussion, we can conclude that there are two factors determining zwitterion formation. The first is the stabilizing interaction of the amino acid-base salt bridge with the narrow $C D$ rim. The second requirement is a GB above a minimum threshold. We have previously shown that bases more signif- icantly than $\mathrm{nPA}$ increase the rate of reaction but not the product outcome [13]. Zwitterionic formation requires a specific interaction between the amino acid and the rim of the cyclodextrin with both the C-and the N-terminus interacting with the narrow rim simultaneously. The size of the cavity plays an important role in determining this interaction. The small cavity size of $\alpha-\mathrm{CD}$ cannot provide the favorable interaction to yield zwitterions, with the exception of proline. As the host cavity increases in size, the number of amino acids yielding ternary product increases. For $\beta-\mathrm{CD}$, the five least basic amino acids formed only gas-phase exchange products with the base nPA. The six most basic amino acids formed only zwitterion complex with nPA. Amino acids of moderate basicity produced a mixture of exchange and zwitterion products. The zwitterion product was favored by the majority of amino acids. Of the 17 studied, 11 formed only zwitterions product, four formed a mixture of zwitterions and exchange products, and only the two least basic amino acids only formed exchange reaction products. In general, the larger cyclodextrins and the more basic amino acids favor the formation of the ternary complex.

The relationship between cavity size and zwitterions stability can also result from the larger number of hydroxyl groups available for hydrogen bonding in the larger host molecules. An increase in the number of hydroxyl groups on the narrow rim of the host increases zwitterion stability. As shown in Scheme 4, during the gas-phase zwitterion formation, the nascent ammonium group of the alkyl amine remains attached to the amino acid and stabilizes the complex. The zwitterion is further stabilized by hydrogen bonding provided by the hydroxyl groups on the narrow rim of the cyclodextrin host. It is not possible to determine specifically the number of hydroxyl groups necessary to stabilize the zwitterionic species because of the structural constraints in the cyclodextrin.

\section{Reactions of Amino Acids and Their Enantiomers}

It has been reported previously that the rates of reaction for the gas-phase exchange in derivatized $\beta$-CD differ among enantiomers [15, 16, 18, 19]. Furthermore, molecular modeling calculations with $\mathrm{L}$ - and D-enantiomers illustrate that the interactions between the amino acid guest and the derivatized $\beta$ CD host produce distinct complex structures $[16,18$, 19].

This study investigates the rates of reaction for underivatized $\beta$-CD:amino acid complexes, $[\alpha-\mathrm{CD}$ :AA $+\mathrm{H}]^{+}$, with a gaseous base (Table 2). Specifically, the rate constants for reactions leading to the formation of the zwitterion and exchange products for underivatized $\beta$-CD complexed to L- and D-enantiomers of 14 amino acids were determined. In these studies, nPA was used as the basic reactant gas for 11 of the amino acids studied. Ethylenediamine (EDA) was used for the three 
Table 2. Rate constants and enantio selectivity of amino acids complexed to $\beta$-CD

\begin{tabular}{|c|c|c|c|c|c|c|}
\hline \multirow[b]{2}{*}{ Amino Acid } & \multicolumn{3}{|c|}{$\beta-C D$} & \multicolumn{3}{|c|}{$\beta-C D^{m}$} \\
\hline & $\mathrm{k}_{\mathrm{L}}$ & $k_{D}$ & $\mathrm{k}_{\mathrm{L}} / \mathrm{k}_{\mathrm{D}}$ & $\mathrm{k}_{\mathrm{L}}$ & $k_{D}$ & $\mathrm{k}_{\mathrm{L}} / \mathrm{k}_{\mathrm{D}}$ \\
\hline \multirow[t]{2}{*}{ Ala } & $1.9^{a}$ & 0.54 & 3.5 & 2.4 & 1.5 & 1.6 \\
\hline & $-{ }^{\mathrm{b}}, \mathrm{c}$ & - & - & - & - & - \\
\hline \multirow[t]{2}{*}{ Asp } & 0.014 & 0.0052 & 2.7 & 0.02 & 0.01 & 2 \\
\hline & - & - & - & - & - & - \\
\hline \multirow[t]{2}{*}{ Val } & 2.3 & 0.61 & 3.8 & 3.1 & 1 & 3.1 \\
\hline & - & - & - & - & - & - \\
\hline \multirow[t]{2}{*}{ Glu } & - & - & - & 0.01 & 0.005 & 2 \\
\hline & 0.0058 & 0.0017 & 3.4 & - & - & - \\
\hline \multirow[t]{2}{*}{ Leu } & 0.32 & 0.082 & 3.9 & 0.5 & 0.14 & 3.6 \\
\hline & 0.38 & 0.091 & 4.2 & - & - & - \\
\hline \multirow[t]{2}{*}{ Ile } & 0.53 & 0.13 & 4.1 & 1 & 0.27 & 3.7 \\
\hline & 0.57 & 0.14 & 4.1 & - & - & - \\
\hline \multirow[t]{2}{*}{ Pro } & 1.6 & 0.3 & 5.3 & & & \\
\hline & 2.2 & 0.46 & 4.7 & & & \\
\hline \multirow[t]{2}{*}{ Thr } & 0.26 & 0.1 & 2.6 & & & \\
\hline & - & - & - & & & \\
\hline \multirow[t]{2}{*}{ Phe } & 1 & 0.48 & 2.1 & 1.4 & 1.7 & 0.82 \\
\hline & 1.7 & 0.94 & 1.8 & - & - & - \\
\hline \multirow[t]{2}{*}{ Tyr } & 0.0073 & 0.0062 & 1.2 & 0.019 & 0.029 & 0.66 \\
\hline & 0.011 & 0.01 & 1.1 & - & - & - \\
\hline \multirow[t]{2}{*}{ GIn } & - & - & - & & & \\
\hline & 0.18 & 0.049 & 3.7 & & & \\
\hline \multirow[t]{2}{*}{$\mathrm{His}^{\mathrm{d}}$} & - & - & - & & & \\
\hline & 0.0043 & 0.0025 & 1.7 & & & \\
\hline \multirow[t]{2}{*}{ Lys $^{d}$} & - & - & - & & & \\
\hline & 0.0058 & 0.0031 & 1.9 & & & \\
\hline \multirow[t]{2}{*}{$\operatorname{Arg}^{d}$} & - & - & - & & & \\
\hline & 0.0092 & 0.0039 & 2.3 & & & \\
\hline
\end{tabular}

${ }^{\text {aRate }}$ constant for exchange reaction values $\times 10^{-11} \mathrm{~cm}^{3} / \mathrm{molecules}$

${ }^{b}$ Rate constant for ternary complex formation values $\times 10^{-11} \mathrm{~cm}^{3} /$ molecules

"“-" indicates this kind of reaction did not occur

${ }^{\mathrm{d}}$ The gas-phase reactions were carried out with ethlyenediamine instead of $n$-propylamine. Histidine, lysine and arginine won't react with $n$-propylamine due to their high gas-phase basicities.

most basic amino acids studied, His, Lys, and Arg, as no reaction was observed with $\mathrm{nPA}$.

The rates of reaction were determined using solutions of a single enantiomer. The intensity of peak, I, corresponding to the amino acid complex, $[\beta-\mathrm{CD}: \mathrm{AA}+$ $\mathrm{H}]^{+}$, were monitored as a function of reaction time. The rate constants were obtained from the pseudo-firstorder kinetic by plotting $\ln \left(\mathrm{I} / \mathrm{I}_{0}\right)$ versus $\mathrm{t}$, where $\mathrm{I}$ is the intensity of the amino acid:cyclodextrin complex at time $t$ and $I_{0}$ is the sum of the intensities of the complex, the exchanged and the ternary product. Figure 3 shows the FTMS spectra of both L- and D-enantiomers, [ $\beta$-CD:Leu $+\mathrm{H}]^{+}$, in the reaction with $\mathrm{nPA}$ at reaction times of 10 and $60 \mathrm{~s}$. The Leu complex yielded both guest exchange and ternary product. Comparing the relative intensities of the exchange product and ternary product at $10 \mathrm{~s}$, the formation of the ternary complex is favored for both Land D-enantiomers. However, at $60 \mathrm{~s}$, the ternary complex is favored in the $\mathrm{L}$ enantiomer and the exchange product is favored in the D enantiomer of Leu. It is evident that the ternary complex is the kinetically favored product for both enantiomers. However, the result at $60 \mathrm{~s}$ shows the exchange product is thermody- namically favored for L-Leu and the ternary complex is favored for D-Leu.

The kinetic plots for the reactions of L- and D-Leu are shown in Figure 3. The kinetic plots depict two linear regions having different slopes. The first region, between 0 and $15 \mathrm{~s}$, has a greater slope than the second region (time $>15 \mathrm{~s}$ ). The existence of two reaction rates can be explained by two reactions occurring simultaneously. During the first $15 \mathrm{~s}$ of the reaction, the reactant, $[\beta-\mathrm{CD}: \mathrm{Leu}+\mathrm{H}]^{+}$, is being depleted by formation of the exchange and zwitterions products. After $15 \mathrm{~s}$ the slope of the kinetic plot becomes less steep and is indicative of a single reaction pathway. Based on the mass spectra of $[\beta \text {-CD:Leu }+\mathrm{H}]^{+}$at 10 and $60 \mathrm{~s}$ (Figure $3)$, it can be deduced that the reaction pathway leading to formation of the exchange product persists after zwitterion formation has ceased.

Molecular dynamic simulations of the $[\beta-\mathrm{CD}: \mathrm{Leu}+$ $\mathrm{H}]^{+}$complexes indicate that the protonated ammonium group preferentially coordinates to the narrow rim of the cyclodextrin [16]. Modeling of the complex resulted in two low-energy structures, which suggests that the complex may exist in two distinct forms. In one struc- 
$[\beta-\mathrm{CD}: \mathrm{D}-\mathrm{Leu}+\mathrm{H}]^{+}$

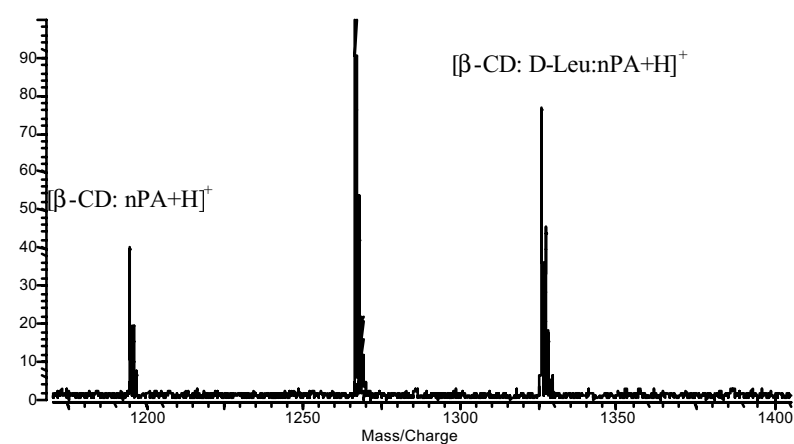

(a)

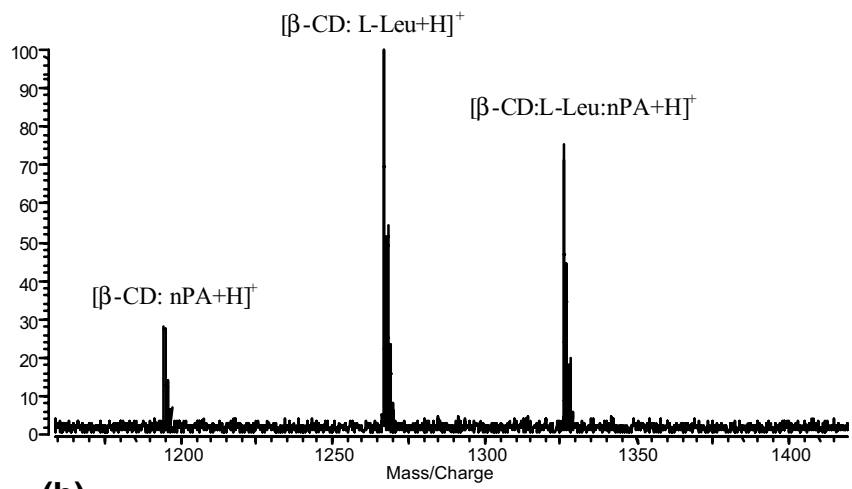

(b)

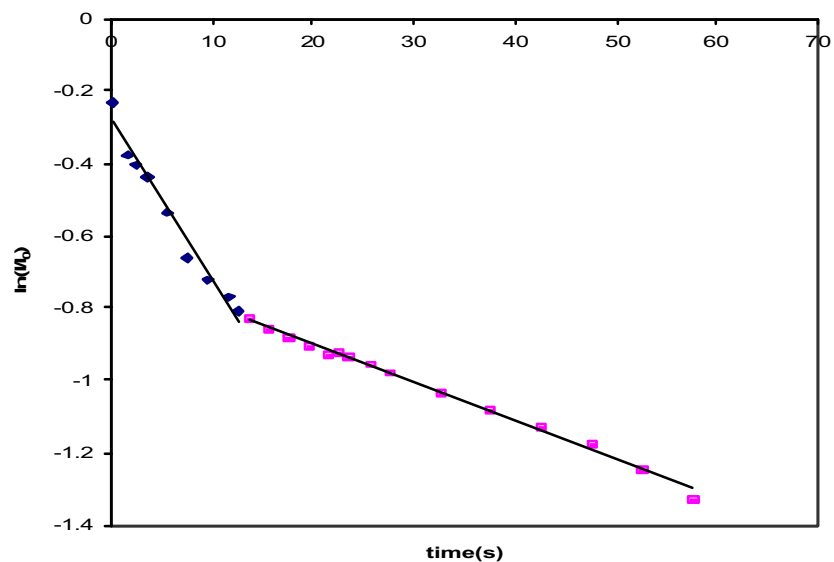

(c)

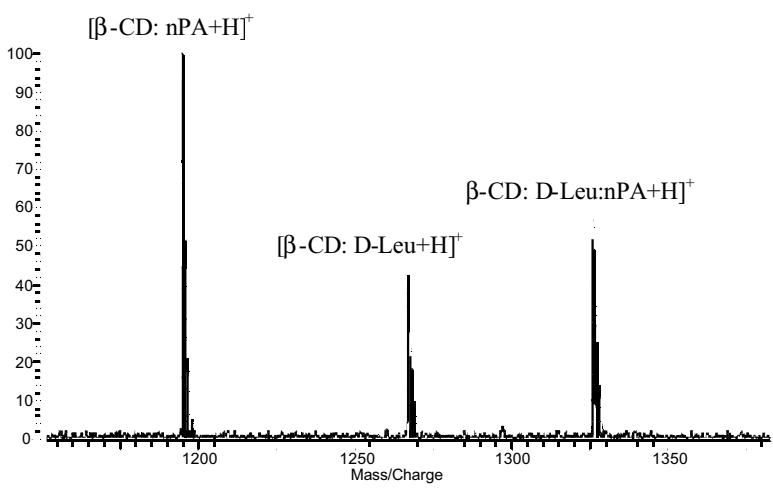

$[\beta-C D: \text { L-Leu:nPA+H }]^{+}$
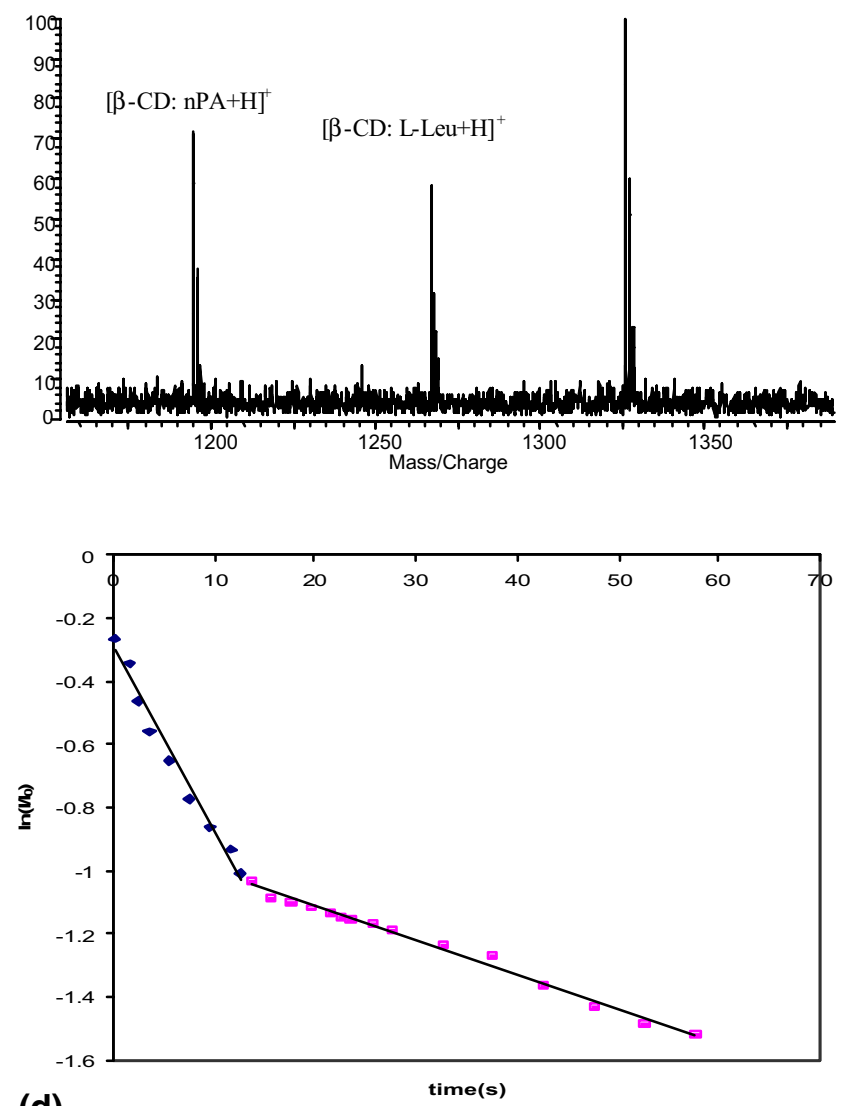

(d)

Figure 3. The FTMS spectra of $[\beta-\mathrm{CD}: \mathrm{Leu}+\mathrm{H}]^{+}$in the reaction with $n$-propylamine (nPA) and the kinetic plots for D ((a) and (c)) and L ((b) and (d)) enantiomers. The Leu complex yielded both guest exchange and ternary products. The kinetic plots ((c) and (d)) yielded two linear components with different slopes. The existence of two reaction rates can be explained by two reactions occurring simultaneously. The reaction time for the spectra shown here are 10,000 ms and 60,000 ms.

ture, known as the "threaded through" structure, the ammonium group interacts with the narrow (lower) rim and the carboxylic acid interacts with the wider rim. In the other, called the "narrow-only" structure, both the carboxylic acid and the ammonium groups interact with the narrow rim [13]. These two forms of the complex $[\beta-\mathrm{CD} \text { :Leu }+\mathrm{H}]^{+}$are likely formed during the ionization event and lead to different reaction channels. A general correlation exists between the lowest energy structure and formation of the ternary complex. Amino acids that yielded the threaded-through structure only produced guest-exchange products, while the narrowonly structure produces mainly zwitterionic product. The presence of two structures for L- and D-Leu is reflected in the kinetic plots showing two rate constants.

The enantiomers of Glu, unlike Leu, reacted with $\mathrm{nPA}$ to form only ternary product as shown in the mass spectra in Figure 4. Mass spectra at reaction times $t=5$ 

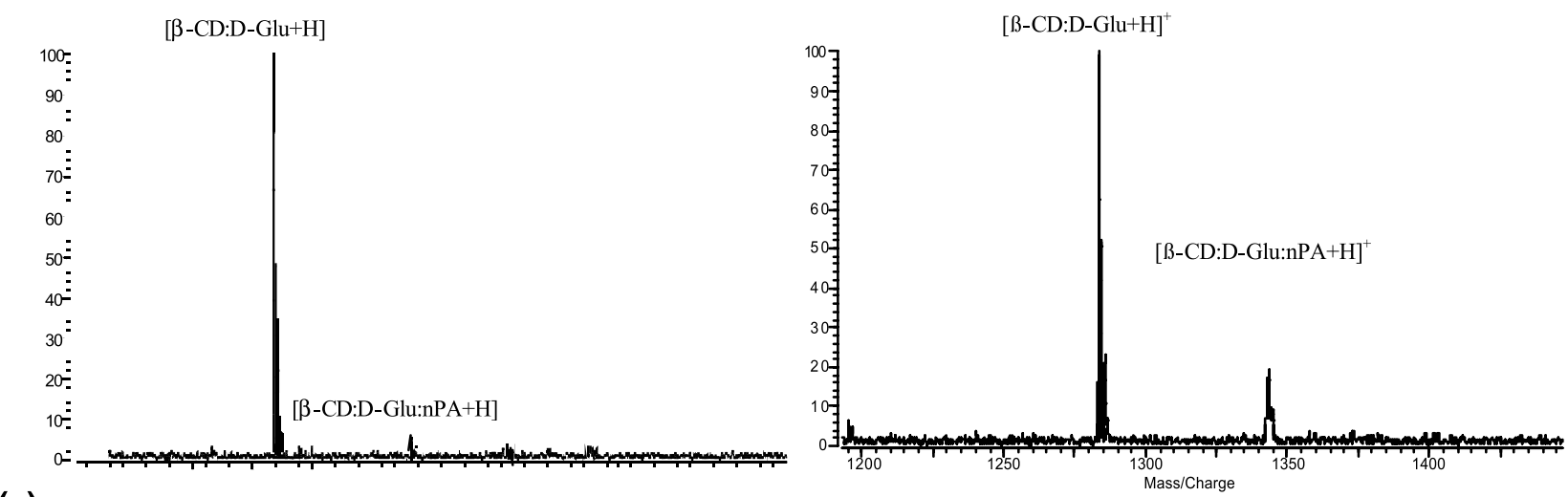

(a)
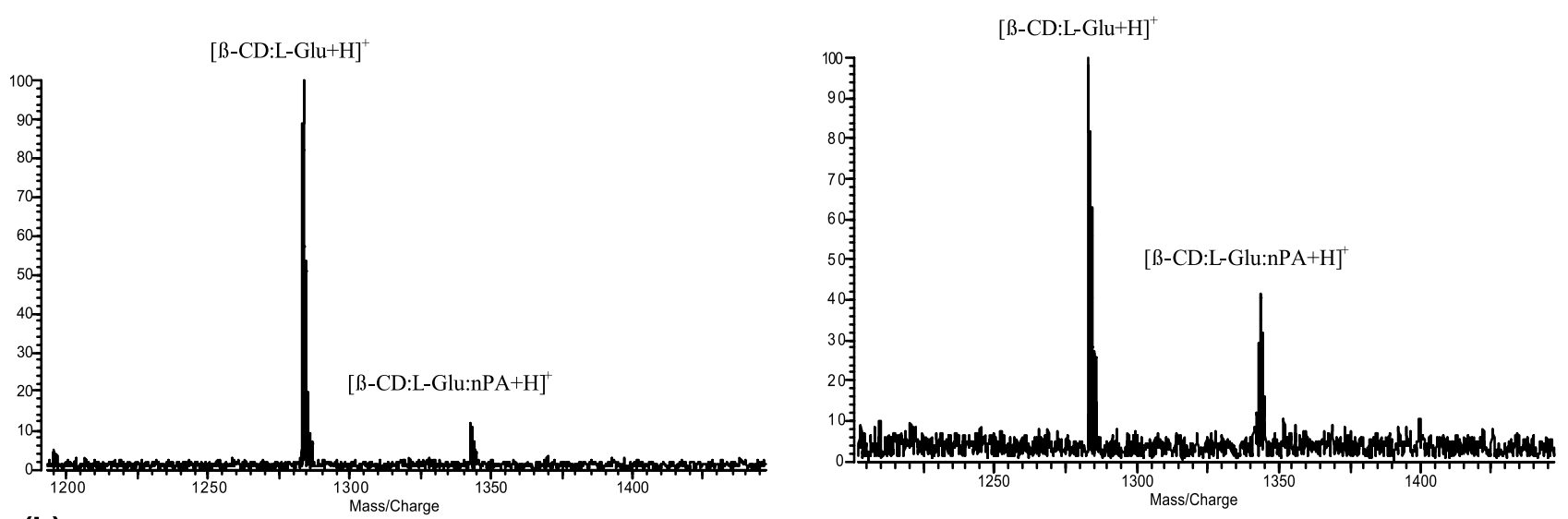

(b)

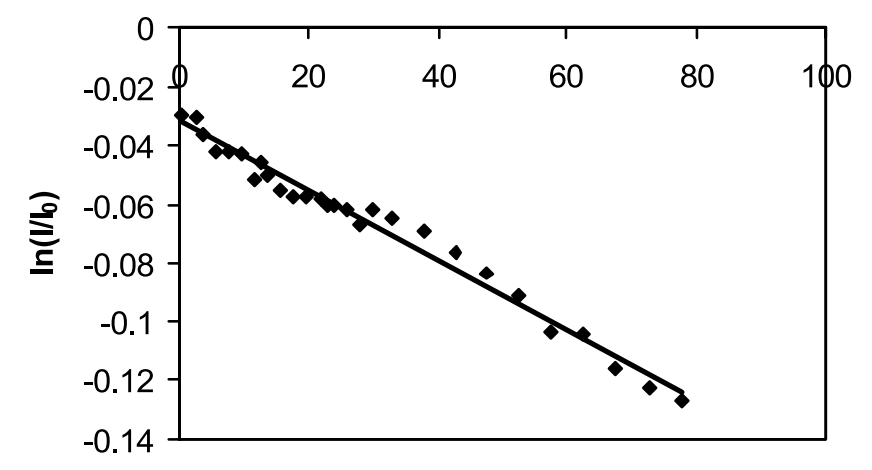

(c) time(s)

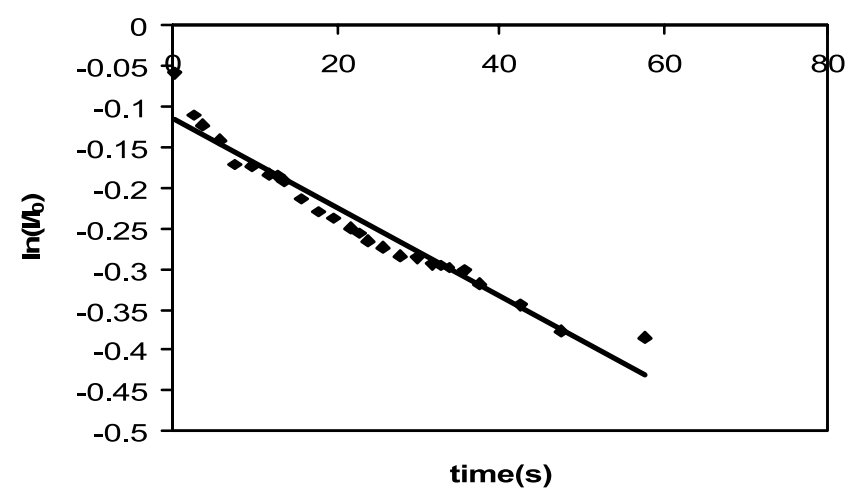

(d)

Figure 4. The FTMS spectra of $[\beta-\mathrm{CD}: \mathrm{Glu}+\mathrm{H}]^{+}$in reaction with $n$-propylamine $(\mathrm{nPA})$ and the kinetic plots for D ((a) and (c)) and L ((b) and (d)) enantiomers. The Glu complex yielded only the ternary product. The kinetic plots show single rate constants. The reaction time for the spectra shown here are $5000 \mathrm{~ms}$ and $60,000 \mathrm{~ms}$.

and $\mathrm{t}=60 \mathrm{~s}$ and the kinetic plots for the reactions are given. The kinetic plots for Glu are notably different than those of Leu, exhibiting a single line. This is in accordance with the Glu mass spectra in which a single product is observed corresponding to the ternary product. Also, the reaction occurs at a noticeably slower rate than Leu. One reason is that there is only one reaction pathway depleting the $\left[\beta\right.$-CD:Glu $+\mathrm{H}^{+}$complex. Another conclusion is based on the molecular modeling, which depicts the Glu carboxylic acid side-chain interacting with the CD upper rim (Figure 5). This hydrogen bonding renders additional stability to the complex and lowers the reactivity.

The interactions leading to the formation of host/ guest complexes are very sensitive to the molecules' structural and chemical characteristics. These characteristics are also keys in zwitterion formation of amino acids. Both amino acids and cyclodextrins are chiral molecules, and together form stereoisomeric complexes. The L- and D-amino acid enantiomers interact 


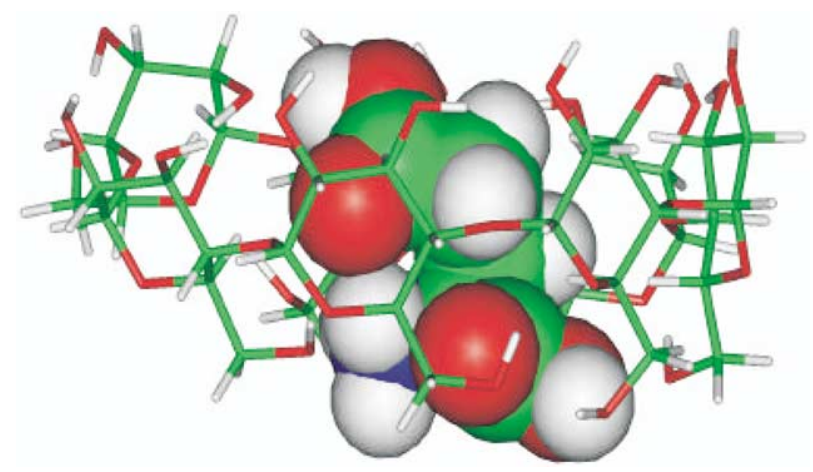

Figure 5. The low energy structure of $[\beta-\mathrm{CD}: \mathrm{Glu}+\mathrm{H}]^{+}$complex. The interaction of carboxylic groups on the side chain of the amino acids and the wide rim of cyclodextrin is evident and may have caused the relatively slow reaction rate.

with cyclodextrin in a unique manner, resulting in reactivity differences for the complexes. It has previously been found that the kinetics of the gas-phase exchange reaction in derivatized $\beta$-CD are different for enantiomers. Molecular modeling calculations of L- and D-enantiomers predict that the interactions between the amino acid guest and the derivatized $\beta$ - CD host produce distinct complex structures [16, 19].

This study investigates the reaction kinetics of underivatized $\beta$-CD:amino acid complexes, $[\beta-\mathrm{CD}: \mathrm{AA}+$ $\mathrm{H}]^{+}$, with the gaseous base nPA. The hydrogen bonding ability of the $\mathrm{CD}$ host plays an important role in complex stabilization. Underivatized $\beta-\mathrm{CD}$, having seven hydroxyl groups on the lower rim, provides many additional interaction sites for the guest molecule relative to derivatized $\beta$ - CD. Probing the reaction kinetics of underivatized and derivatized $\beta$ - CD complexes provides an understanding of the structural factors determining reactivity.

The rate constants for reactions leading to the formation of the zwitterion and exchange products between underivatized $\beta$-CD and the L- and D-enantiomers of 14 amino acids were determined. In these studies, nPA was used as the basic reactant gas for 11 of the amino acids studied. Ethylenediamine (EDA) was used for the three most basic amino acids studied, His, Lys, and Arg, as no reaction was observed with $\mathrm{nPA}$. Important information regarding the effect of structural features on reaction kinetics was deduced.

The rates of reaction were determined using solutions of a single enantiomer. The enantiomeric selectivity was calculated as the ratio of rate constants for the Land D-amino acids, $\mathrm{k}_{\mathrm{L}} / \mathrm{k}_{\mathrm{D}}$. Alanine produced only exchange product, from which the selectivity was determined to be 3.5. This value was slightly lower than the other amino acids with alkyl side chains such as Val, Leu, and Ile, which exhibited selectivities of 3.8, 3.9, and 4.1 , respectively for exchange reaction. Leu and Ile also formed ternary product and their selectivities, 4.2 and 4.1 , respectively, were similar to those in the exchange reaction,. This reaction trend can be explained by the three-point model [16]. The three-point attachment refers to three factors, two attractive and one repulsive, which dictate amino acid binding in the CD cavity. The ammonium and the carboxylic acid groups are attracted to the $\mathrm{CD}$ cavity and rim through hydrogen bonding, whereas the steric interaction of the side-chain creates a repulsive force. The repulsive interaction between the host and the guest molecules increases as the side-chain size increases. For complex stability, the overall attractive forces must dominate the repulsive forces between the amino acid and CD. The attractive interactions are maximized by optimizing the hydrogen bonding between the $\mathrm{C}$ and $\mathrm{N}$-terminus and the $\mathrm{CD}$ cavity. The repulsive force is minimized by orientating the sidechain to reduce steric repulsion. Thus, the L- and D-amino acids are forced to adopt unique conformations which lead to enantioselectivity.

The chiral selectivity of the aromatic amino acids is much lower than those with alkyl side chains. Phenylalanine and tyrosine showed enantioselectivity of 2.1 and 1.2 for exchange reaction and 1.8 and 1.1 for zwitterion formation, respectively. This can be explained by the molecular modeling of Phe which illustrates that inside the cyclodextrin cavity, both the $\mathrm{N}$ and the C-terminus interact with the lower rim. The inflexible phenyl ring is forced into similar, sterically acceptable conformations for both enantiomers that do not contribute to stereo selectivity (Figure 6).

Amino acids Glu and Asp, which have acidic side chains, display a high degree of enantioselectivity. Glu, which produced only zwitterion product, had a selectivity of 3.4. Contrastingly, Asp produced only exchange product and yielded a selectivity of 2.7.

\section{Chiral Analysis Amino Acids from Bacillus licheniformis Cell Wall}

To demonstrate the application of this technique we isolated the Poly- $\gamma$-D-glutamyl capsular polymer from the outermost cell periphery of the bacteria Bacillus licheniformis and performed chiral analysis. The Glu

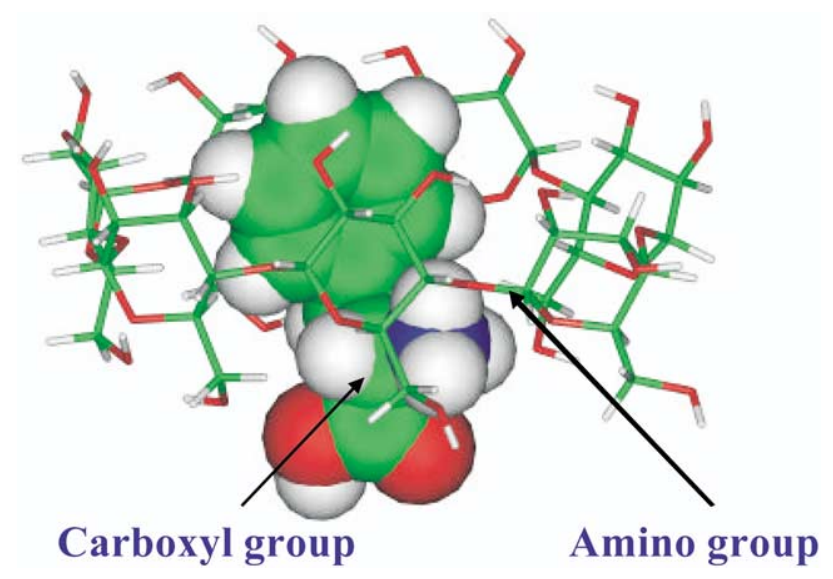

Figure 6. Low energy structures of $[\beta-\mathrm{CD}: \mathrm{Phe}+\mathrm{H}]^{+}$complex. 


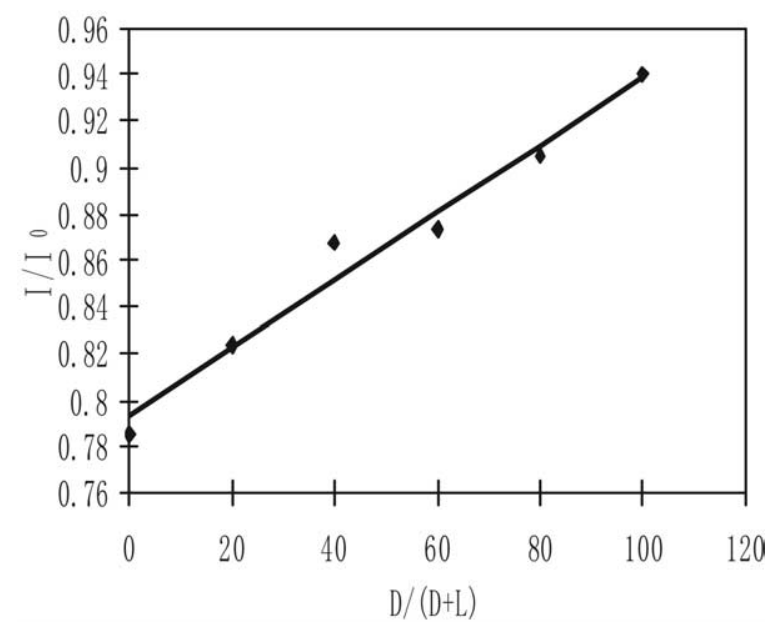

Figure 7. The calibration curve for the racemic mixtures of Glu.

polymer was first isolated and characterized by Troy [64, 65].

In our experiment, the enantiomeric Glu mixtures were obtained from Troy's lab. A calibration curve was constructed by analyzing known mixtures of L- and D-Glu enantiomers (Figure 7). The parameters of alkyl amine, its pressure, and the reaction time were optimized for optimal enantioselectivity and short reaction times. For the calibration curve, the Glu enantiomeric composition was varied in this manner (L:D): 100:0, 80:20, 60:40, 40:60, 20:80, 0:100. Mass spectra for these mixtures were obtained at the chosen reaction time $(60$ s). From the mass spectra, a calibration curve is constructed with the ordinate $I / I_{0}$, with $I$ as product peak and $\mathrm{I}_{0}$ the sum of the reactant peak intensity and product peak intensity. The abscissa is $D /(D+L)$, the D-Glu enantiomer mole fraction. Measuring the $\mathrm{I} / \mathrm{I}_{0}$ ratio of an unknown mixture L-Glu and D-Glu under the identical conditions to which the calibration data were obtained allowed the corresponding unknown mole fraction to be determined. This yields a $7.8 \% \mathrm{~L}-\mathrm{Glu}$ with the remainder being D-Glu. This result is in excellent agreement with the previous results of $7 \sim 10 \%$ L-Glu.

\section{Conclusions}

Gas-phase complexes of $\mathrm{CD}$ and amino acids represent a model in which function, the ability to produce zwitterionic forms, is dictated by structural parameters of host/guest complex. It was found that the formation of gas-phase zwitterions in CD was favored by amino acids with high gas-phase basicities. Deprotonation of the amino acid by the neutral alkyl amine forms a salt-bridge complex, which is stabilized by the hydroxyl groups of the CD lower rim (Scheme 4). Stabilization of the ternary product necessitates interaction with the cyclodextrin rim. The geometry and size of the host and guest molecules specify the interactions that lead to the conformation of the complex. The conformation then determines reaction pathway, e.g., zwitterion formation or exchange reaction that is favored. Larger host cavities and more hydroxyl groups on the narrow rim are favorable to stabilize amino acid zwitterion in the cavity. The linear oligosaccharide Mhep was unable to stabilize any zwitterion species for amino acids. This suggests that the interaction with the narrow rim of the well-defined CD cavity creates a stabilizing environment for the zwitterion.

It has also been demonstrated that the two reaction channels, zwitterion formation and guest exchange, yield similar levels of enantioselectivity. However, in general the enantioselectivity in the underivatized $\beta$-CD complexes are higher than those for permethylated $\beta-\mathrm{CD}$ for the exchange reaction, albeit the rates of reaction are also lower. In applications where enantiomeric excess are desired, it may in some cases be more beneficial to use underivatized cyclodextrin.

\section{References}

1. Hanessian, S.; Gallagher, R. T.; Ball, C. P.; Gatehouse, D. R.; Gates, P. J.; Lobell, M.; Derrick, P. J. Crystal Structures and Molecular Conformations of Cyclodextrins. Tetrahedron 1995, 51, 10149-10158.

2. Li, S.; Purdy, W. C. Cyclodextrin Review. Chem. Rev. 1992, 92, 14571490 .

3. Szejtli, J. Cyclodextrins and Their Inclusion Complexes; Akadémiai Kiadó: Budapest, Hungary 1982, p 17

4. Szejtli, J. Cyclodextrin Technology; Kluwer Academic Publisher: Boston 1988 , p 385.

5. Szejtli, J. Introduction and General Overview of Cyclodextrin Chemistry. Chem. Rev. 1998, 98, 1743-1753.

6. Cescutti, P.; Garozzo, P.; Rizzo, R. Study of the Inclusion Complexes of Aromatic Molecules with Cyclodextrins Using Ionspray Mass Spectrometry. Carbohydr. Res. 1996, 290, 105-115.

7. Cunniff, J. B.; Vouros, P. False Positives and the Detection of Cyclodextrin Inclusion Complexes by Electrospray Mass Spectrometry. J. Am. Soc. Mass Spectrom. 1995, 6, 437-447.

8. Gallagher, R. T.; Ball, C. P.; Gatehouse, D. R.; Gates, P. J.; Lobell, M.; Derrick, P. J. Cyclodextrin-Piroxicam Inclusion Complexes: Analyses by Mass Spectrometry and Molecular Modelling. Int. J. Mass Spectrom. Ion Processes 1997, 165/167, 523-531.

9. Garcia, B.; Ramirez, J.; Wong, S.; Lebrilla, C. B. Thermal Dissociation of Protonated Cyclodextrin-Amino Acid Complexes in the Gas Phase. Int. J. Mass Spectrom. 2001, 210/211, 1-3.

10. Kellersberger, K. A.; Dejsupa, C.; Liang, Y.; Pope, R. M.; Dearden, D. V. Gas Phase Studies of Ammonium-Cyclodextrin Compounds Using FT-ICR. Int. J. Mass Spectrom. 1999, 193, 181-195.

11. Ramanathan, R.; Prokai, L. Electrospray Ionization Mass Spectrometric Study of Encapsulation of Amino Acids by Cyclodextrins. J. Am. Soc. Mass Spectrom. 1995, 6, 866-871.

12. Dearden, D. V.; Liang; Y.; Nicoll, J. B.; Kellersberger, K. A. Study of Gas-Phase Molecular Recognition Using Fourier Transform Ion Cyclotron Resonance Mass Spectrometry (FTICR/MS). J. Mass Spectrom. 2001, 36, 989-997.

13. Ahn, S. C. X.; Lebrilla, C. B.; Gronert, S. Zwitterion Formation in Gas-Phase Cyclodextrin Complexes. J. Am. Soc. Mass Spectrom. 2005, 16, 166-175.

14. Grigorean, G.; Lebrilla, C. B. Enantiomeric Analysis of Pharmaceutical Compounds by Ion/Molecule Reactions. Anal. Chem. 2001, 73, 16891691.

15. Ramirez, J.; Ahn, S.; Grigorean, G.; Lebrilla, C. B. Evidence for the Formation of Gas-Phase Inclusion Complexes with Cyclodextrins and Amino Acids. J. Am. Chem. Soc. 2000, 122, 6881-6890.

16. Ahn, S.; Ramirez, J.; Grigorean, G.; Lebrilla, C. B. Chiral Recognition in Gas-Phase Cyclodextrin:Amino Acid Complexes-Is the Three Point Interaction Still Valid in the Gas Phase? J. Am. Soc. Mass Spetrom. 2001, 12, 278-287.

17. Camilleri, P.; Haskins, N. J.; New, A. P.; Saunders, M. R. Analyzing the Complexation of Amino Acids and Peptides with b-Cyclodextrin Using Electrospray Ionization Mass Spectrometry. Rapid Commun. Mass Spectrom. 1993, 7, 949-952.

18. Grigorean, G. G., Scott; Lebrilla, C. B. Enantioselective Gas-Phase Ion-Molecule Reactions in a Quadrupole Ion Trap. Int. J. Mass Spectrom. 2002, 219, 79-87. 
19. Ramirez, J.; He, F.; Lebrilla, C. B. Gas-Phase Chiral Differentiation of Amino Acid Guests in Cyclodextrin Hosts. J. Am. Chem. Soc. 1998, 120, 7387-7388.

20. Grigorean, G. C.; Xin; Lebrilla, C. B. Chiral Analyses of Peptides by Ion/Molecule Reactions. Int. J. Mass Spectrom. 2004, 234, 71-77.

21. Grigorean, G.; Ramirez, J.; Ahn, S. H.; Lebrilla, C. B. A Mass Spectrometry Method for the Rapid Determination of Enantiomeric Excess in Mixtures of D, L-Amino acids. Anal. Chem. 2000, 72, 4275-4281.

22. Speranza, M. Enantioselectivity in Gas-Phase Ion-Molecule Reactions. Int. J. Mass Spectrom. 2004, 232, 277-317.

23. Scuderi, D.; Paladini, A.; Satta, M.; Catone, D.; Filippi, A.; Piccirillo, S.; Lagana, A.; Speranza, M.; Guidoni, A. Giardini. Gas-Phase Complexes: Noncovalent Interactions and Stereospecificity. Int. J. Mass Spectrom. 2003, 223/224, 159-168

24. Botta, B.; Botta, M.; Filippi, A.; Tafi, A.; Delle Monache, G.; Speranza, M. Enantioselective Guest Exchange in a Chiral Resorcin[4]arene Cavity. J. Am. Chem. Soc. 2002, 124, 7658-7659.

25. Paladini, A. C. C.; Di Palma, T.; Speranza, M.; Lagana, A.; Fago, G.; Filippi, A.; Satta, M.; Guidoni, A. G. Enantiodiscrimination of ChiralAminophosphonic Acids by Mass Spectrometry. Chirality 2001, 13, 707-711.

26. Filippi, A. G. A.; Piccirillo, S.; Speranza, M. Gas-Phase enantioselectivity. Int. J. Mass Spectrom. 2000, 198, 137-163.

27. Tafi, A.; Botta, B.; Botta, M.; Giuliano, D.M.; Filippi, A.; Speranza, M.; Chiral recognition by resorcin[4]arene receptors: Intrinsic kinetics and dynamics. Eur. J. Chem. 2004, 10, 4126-4135.

28. Speranza, M. S.; Mauro; Piccirillo, Susanna; Rondino, Flaminia; Paladini, Alessandra; Giardini, Anna; Filippi, Antonello; Catone, Daniele. Chiral recognition by mass-resolved laser spectroscopy. Mass Spectrom. Rev. 2005, 24, 588-610.

29. Wu, L. M.; Tao, W. A.; Cooks, G. R. Ligand and metal-ion effects in metal-ion clusters used for chiral analysis of -hydroxy acids by the kinetic method. Anal. Bioanal. Chem. 2002, 373, 618-627.

30. Tao, W. A.; Zhang, D. X.; Nikolaev, E. N.; Cooks, G. R. Copper (II)-Assisted Enantiomeric Analysis of D, L-Amino Acids using the Kinetic Method: Chiral Recognition and Quantification in the gas phase. J. Am. Chem. Soc. 2000, 122, 10598-10609.

31. Tao, W. A.; Zhang, D. X.; Wang, F.; Thomas, P. D.; Cooks, G. R. Kinetic Resolution of D, L-Amino Acids based on Gas-Phase Dissociation of Copper(II) Complexes. Anal. Chem. 1999, 71, 4427-4429.

32. Paladini, A.; Calcagni, C.; Di Palma, T.; Satta, M.; Speranza, M.; Scuderi, D.; Lagana, A.; Fago, G.; Guidoni, A. Giardini. Laser production of gas phase complexes of metal -aminophosphonic acid mixtures and their role in chiral recognition. Int. I. Photoenergy 2001, 3, 217-221.

33. Wu, L.; Meurer, E. C.; Cooks, R. G. Chiral Morphing and Enantiomeric Quantification in Mixtures by Mass Spectrometry. Anal. Chem. 2004, 76, 663-671.

34. Wu, L. M.; Tao, W. A.; Cooks, G. R. Kinetic method for the simultaneous chiral analysis of different amino acids in mixtures. J. Mass Spectrom. 2003, 38, 386-393

35. Tao, W. A.; Clark R. L.; Cooks, G. R. Quotient Ratio Method for Quantitative Enantiomeric Determination by Mass Spectrometry. Anal. Chem. 2002, 74, 3783-3789.

36. Tao, W. A.; Wu; L. M.; Cooks, G. R.; Wang, F.; Begley, J. A.; Lampert, B. Rapid Enantiomeric Quantification of an Antiviral Nucleoside Agent (D, L-FMAU, 2'-Fluoro-5-Methyl-b, D, L-Arabinofurano-Syluracil) by Mass Spectrometry. J. Med. Chem. 2001, 44, 3541-3544.

37. Tao, W. A. G.; Fabio, C.; Cooks, G. R. Mass Spectrometric Quantitation of Chiral Drugs by the Kinetic Method. Anal. Chem. 2001, 73, 1692-1698.

38. Lu, H.-J.; Guo, Y.-L. Evaluation of Chiral Recognition Characteristics of Metal and Proton Complexes of Di-o-Benzoyl-Tartaric Acid Dibutyl Ester and L-Tryptophan in the Gas Phase. J. Am. Soc. Mass Spectrom. 2003, 14, 571-580

39. Lu, H.-J.; Guo, Y.-L. Chiral Recognition of Borneol by Association with Zinc(II) and L-Tryptophan in the Gas Phase. Anal. Chim. Acta 2003, 482, $1-7$.

40. Sawada, M. Chiral Recognition Detected by Fast Atom Bombardment Mass Spectrometry. Mass Spectrom. Rev. 1997, 16, 73-90.

41. Sawada, M.; Okumura, Y.; Shizuma, M.; Takai, Y.; Hidaka, Y.; Yamada, H.; Tanaka, T.; Kaneda, T.; Hirose, K.; et al. Enantioselective Complexation of Carbohydrate or Crown Ether Hosts with Organic Ammonium Ion Guests Detected by FAB mass spectrometry. J. Am. Chem. Soc. 1993, 115, 7381-7388.

42. Sawada, M.; Okumura, Y.; Yamada, H.; Takai, Y.; Takahashi, S.; Kaneda, T.; Hirose, K.; Misumi, S. Cross-Chiral Examinations Of Molecular Enantioselective Recognition By Fast Atom Bombardment Mass Spectrometry Host-Guest Complexations Between Chiral Crown Ethers and Chiral Organic Ammonium Ions. Org. Mass Spectrom. 1993, $28,1525-1528$

43. Sawada, M.; Shizuma, M.; Takai, Y.; Yamada, H.; Kaneda, T.; Hanafusa, T. Enantioselectivity in FAB Mass Spectrometry. J. Am. Chem. Soc. 1992, 114, 4405-4406.
44. Sawada, M.; Takai, Y.; Kaneda, T.; Arakawa, R.; Okamoto, M.; Doe, H.; Matsuo, T.; Naemura, K.; Hirose, K.; Tobe, Y. Chiral Molecular Recognition in Electrospray Ionization Mass Spectrometry. Chem. Commun. 1996, 1735-1736.

45. Sawada, M.; Chiral Recognition in Host-Guest Complexation Determined by the Enantiomer-Labeled Guest Method Using Fast Atom Bombardment Mass Spectrometry. J. Am. Chem. Soc. 1995, 117, 77267736 .

46. Sawada, M.; Takai, Y.; Yamada, H.; Hirayama, S.; Kaneda, T.; Tanaka, T.; Kamada, K.; Mizooku, T.; Takeuchi, S.; et al. Chiral Recognition in Molecular Complexation for the Crown Ether-Amino Ester System. A Facile FAB Mass Spectrometric Approach. Chem. Commun. 1994, 24972498.

47. Sawada, M.; Takai, Y.; Yamada, H.; Kaneda, T.; Kamada, K.; Mizooku, T.; Hirose, K.; Tobe, Y.; Naemura, K. Chiral Amino Acid Recognition Detected by Electrospray Ionization (ESI) and Fast Atom Bombardment (FAB) Mass Spectrometry (MS) Coupled with the Enantiomer-Labeled (EL) Guest Method. J. Chem. Soc. Perkins Trans. II 1998, 3, 701-710.

48. Latini, A.; Toja, D.; Giardini-Guidoni, A.; Palleschi, A.; Piccirillo, S.; Speranza, M. Spectroscopic Enantiodifferentiation of Chiral Molecules in the Gas Phase. Chirality 1999, 11, 376-380.

49. Piccirillo, S.; Rondino, F.; Catone, D. Guidoni, A. G.; Paladini, A. Tacconi, M.; Satta, M.; Speranza, M.; Excitation, Ionization, and Fragmentation of Chiral Molecules in Asymmetric Microenvironments: A Mass-Resolved R2PI Spectroscopic Study. J. Phys. Chem. A 2005, 109, 1828-1835.

50. Botta, B.; Subissati, D.; Tafi, A.; Delle Monache, G.; Filippi, A.; Speranza, M. Host-guest systems: Cavity Effects on the Enantioselectivity of Chiral Amido[4]Resorcinarene Stereoisomers. Angew. Chem. Int. Ed. 2004, 43 4767-4770.

51. Botta, B.; Botta, M.; Filippi, A.; Tafi, A.; Delle Monache, G.; Speranza, M. Enantioselective Guest Exchange in a Chiral Resorcin[4]Arene Cavity. J. Am. Chem. Soc. 2002, 124, 7658-7659.

52. Filippi, A.; Speranza, M. Gas-Phase Reactivity of Diastereomeric Acetate Ion/Tributylborate Complexes. Int. J. Mass Spectrom. 2000, 199, 211-219.

53. Bagheri, H.; Chen, H.; Cooks, G. R. Chiral Recognition by Proton Transfer Reactions with Optically Active Amines and Alcohols. Chem. Commun. 2004, 2740-2741.

54. Gordon, M. S.; Jensen, J. H. Understanding the Hydrogen Bond Using Quantum Chemistry. Acc. Chem. Res. 1996, 29, 536-543.

55. Jensen, J. H.; Gordon, M. S. On the Number of Water Molecules Necessary to Stabilize the Glycine Zwitterion. J. Am. Chem. Soc. 1995, $117,8159-8170$.

56. Kassab, E.; Langlet, J.; Evleth, E.; Akacem, Y. Theoretical Study of Solvent Effect on Intramolecular Proton Transfer of Glycine. J. Mol. Struct. Theochem. 2000, 531, 267-282.

57. Chapo, C. J.; Paul, J. B.; Provencal, R. A.; Roth, K.; Saykally, R. J.; Raposo, C.; Wilcox, C. S. Is Arginine Zwitterionic or Neutral in the Gas Phase? Results from IR Cavity Ringdown Spectroscopy. J. Am. Chem. Soc. 1998, 120, 12956-12957.

58. Raposo C, W.C. The Intramolecular Salt Effect in Chiral Auxiliaries. Enhanced Diastereoselectivity in a Nitrile Oxide Cycloaddition via Rational Transition State Stabilization. Tetrahedron Lett. 1999, 40, 12851288.

59. Spencer, T. A.; Onofrey, T. J.; Cann, R. O.; Russel, J. S.; Lee, L. E.; Blanchard, D. E.; Castro, A.; Gu, P.; Jiang, G.; Shechter, I. Zwitterionic Sulfobetaine Inhibitors of Squalene Synthase. J. Org Chem. 1999, 64, 807-818.

60. Gard, E. E.; Green, K. M.; Warren, H.; Camara, E. J. O.; He, F.; Penn, S. G.; Lebrilla, C. B. A Dual Vacuum Chamber Fourier Transform Mass Spectrometer with Rapidly Interchangeable FAB, MALDI, and ESI Sources: Electrospray Results. Int. J. Mass Spectrom. Ion Processes 1996, 157/158, 115-127.

61. Carroll, J. A.; Penn, S. G.; Fannin, S. T.; Wu, J.; Cancilla, M. T.; Green, M. K.; Lebrilla, C. B. A Dual Vacuum Chamber Fourier Transform Mass Spectrometer with Rapidly Interchangeable LSIMS, MALDI, and ESI Sources: Initial Results with LSIMS and MALDI. Anal. Chem. 1996, 68, 1798-1804.

62. Penn, S. G.; He, F.; Lebrilla, C. B. Peptides Complexed to Cyclodextrin Fragment Rather than Dissociate when Subjected to Blackbody Infrared Radiation D. J. Phys. Chem. 1998, 102, 9119-9126.

63. Hunter, E. P. L.; Lias, S. G. Evaluated Gas Phase Basicities and Proton Affinities of Molecules: An Update. J. Phys. Chem. Ref. Data 1998, 27, $413-656$.

64. Troy, F. A. Chemistry and Biosynthesis of the Poly ( $\gamma$-D-glutamyl) Capsule in Bacillus licheniformis. I. Properties of the MembraneMediated Biosynthetic Reaction. J. Biol. Chem. 1973, 248, 305-315.

65. Troy, F. A. Chemistry and Biosynthesis of the Poly $(\gamma$-D-glutamyl) Capsule in Bacillus licheniformis. II. Characterization and structural properties of the enzymically synthesized polymer. J. Biol. Chem. 1973, $248,316-324$. 